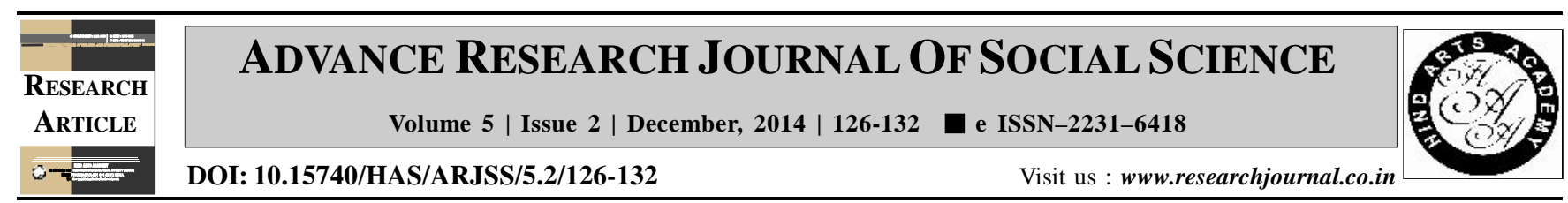

\title{
The impact of socio-demographic characteristics on adolescents' prosocial behaviour
}

Ankita

Department of Home Science, Banasthali Vidyapeeth, BANASTHALI (RAJASTHAN) INDIA

(Email: ankitaagrawal.1205@gmail.com)

\section{ARTICLE INFO :}

$\begin{array}{lll}\text { Received } & : & 10.09 .2014 \\ \text { Revised } & : & 20.10 .2014 \\ \text { Accepted } & : & 03.11 .2014\end{array}$

\section{KEY WORDS :}

Adolescent, Prosocial behaviour, Sociodemographic characteristics

\section{HOW TO CITE THIS ARTICLE :}

Ankita (2014). The impact of socio-demographic characteristics on adolescents' prosocial behaviour. Adv. Res. J. Soc. Sci., 5 (2) : 126-132.

\begin{abstract}
The purposes of this study were to increase understanding of association between adolescent's prosocial behaviour and socio-demographic characteristics. Results of this study indicate that among the age group 13-16 years, adolescents from the age group 13-14 years studying in grade seven show high prosocial behaviour than others. In overall scores, girls exhibited more prosocial behaviour than boys. Private school adolescents exhibited more prosocial behaviour than adolescents of government school. Results show that adolescents belonging to middle socioeconomic status show high prosocial behaviour than low socio- economic status. Adolescents of educated parents show high prosocial behaviour than adolescents of illiterate parents. Adolescents belonging to joint family show higher level of prosocial behaviour than adolescents' from nuclear family. Adolescents having one or two sibling show high prosocial behaviour than adolescents having no siblings or three or more siblings. Chi-square value shows association between socio-demographic characteristics and prosocial behaviour. It shows that prosocial behaviour among adolescents is dependent on socio-demographic characteristics.
\end{abstract}

